\title{
Impact of correctable mediolateral tibiofemoral subluxation on unicompartmental knee arthroplasty implant survival in patients with anteromedial osteoarthritis
}

\author{
Christiaan R Oosthuizen, ${ }^{1 *(\mathbb{D})}$ Innocent Maposa, ${ }^{2}$ Sebastian Magobotha, ${ }^{3}$ Hemant Pandit ${ }^{4}$ \\ ${ }^{1}$ Private Orthopaedic Practice, Johannesburg, South Africa; and Division of Orthopaedic Surgery, University of the Witwatersrand, Johannesburg, \\ South Africa \\ ${ }^{2}$ Faculty of Health Sciences, Health Sciences Research Office, University of the Witwatersrand, Johannesburg, South Africa \\ ${ }^{3}$ Division of Orthopaedic Surgery, University of the Witwatersrand, Johannesburg, South Africa \\ ${ }^{4}$ Leeds Institute of Rheumatic and Musculoskeletal Medicine (LIRMM), Chapel Allerton Hospital and University of Leeds, United Kingdom
}

*Corresponding author: c-c@mweb.co.za

Citation: Oosthuizen CR, Maposa I, Magobotha S, Pandit H. Impact of correctable mediolateral tibiofemoral subluxation on unicompartmental knee arthroplasty implant survival in patients with anteromedial osteoarthritis. SA Orthop J 2021;20(4):196-201. http://dx.doi. org/10.17159/2309-8309/2021/ v20n4a1

Editor: Dr David North, Paarl Hospital, Western Cape, South Africa

Received: October 2020

Accepted: November 2020

Published: November 2021

Copyright: @ 2021 Oosthuizen $\mathrm{CR}$. This is an open-access article distributed under the terms of the Creative Commons Attribution Licence, which permits unrestricted use, distribution and reproduction in any medium, provided the original author and source are credited.

Funding: No benefits in any form have been received from a commercial party related directly or indirectly to the subject of this article.

Conflict of interest: The authors declare they have no conflicts of interest.

\section{Abstract \\ Background}

Medial unicompartmental knee arthroplasty (UKA) is advocated for treating symptomatic anteromedial osteoarthritis (AMOA). Correctable mediolateral tibiofemoral (TF) subluxation can be safely ignored according to the UKA enthusiasts. However, no clinical studies compare the results in AMOA patients with and without subluxation. This study reports the early prospective clinical outcomes of medial UKA in AMOA, with and without correctable mediolateral TF subluxation and the comparison to the retrospective larger patient cohort.

\section{Methods}

The results of an initial retrospective study $(R)$ consisting of 436 consecutive UKA cases (patients treated from May 2012 to October 2017) were compared to a prospective study (P) consisting of 272 consecutive UKA cases in 248 patients with AMOA (evaluated from November 2017 to May 2020). All patients in both cohorts underwent cementless Oxford UKA and were classified into two groups: group 1 (AMOA without mediolateral subluxation) and group 2 (AMOA with mediolateral subluxation) on anteroposterior (AP) radiological knee stress views. Survival analysis methods (Kaplan-Meier and logrank test) were utilised to compare implant survival between the two groups ( 1 and 2 ) and the cohorts ( $R$ and $P$ ). The multivariable Cox proportional hazards model was used to determine risk factors for time to revision.

\section{Results}

The two cohorts, $\mathrm{R}$ and $\mathrm{P}$, had patient groups (group 1 vs group 2) matched for age, sex, wear pattern, preoperative Oxford Knee Score and follow-up period. The overall implant survival for the $\mathrm{P}$ cohort that had at least 20 months of follow-up was $98 \%$. The overall implant survival for group $1(99 \%)$ was significantly better compared to group 2 (93\%). These results are amplified in the R cohort with an average follow-up of 54 months, and with the group 1 survival at $97 \%$ and group 2 at $86 \%$. Subsequent months of follow-up show more failures in group 2 compared to group 1. Patient-reported outcome measures (PROMs) and range of movement were similar for both groups.

\section{Conclusion}

Patients with AMOA and correctable mediolateral TF subluxation have a significantly higher risk of implant failure compared to those without subluxation. This study establishes this association, which has an important implication on patient selection, but does not confirm causality.

Level of evidence: Level 4

Keywords: unicompartmental knee arthroplasty, partial, osteoarthritis, X-ray, implant 


\section{Introduction}

Medial unicompartmental knee arthroplasty (UKA) is advocated for treating symptomatic anteromedial osteoarthritis (AMOA) By definition, AMOA has bone-on-bone medial compartment osteoarthritis (OA) in the presence of intact ligaments and a functionally intact lateral tibiofemoral (TF) compartment. ${ }^{1}$ To confirm the diagnosis of AMOA, use of varus and valgus stress radiographs in addition to weight-bearing anteroposterior (AP) and lateral radiographs is recommended. ${ }^{2}$ These radiographs are performed with the patient lying supine and the knee under study flexed at $20^{\circ}$, with either manual or aided stress applied to the knee. The technique is well described elsewhere. ${ }^{2} \mathrm{~A}$ varus stress radiograph is the most reliable radiographic method to demonstrate full thickness loss of articular cartilage (bone-on-bone contact) between the medial femoral and tibial condyles. ${ }^{2,3} \mathrm{~A}$ valgus stress radiograph helps confirm normal thickness of articular cartilage in the lateral TF compartment and demonstrates that the intraarticular varus deformity is correctable (i.e., the medial collateral ligament is not shortened). In patients with AMOA, the wear pattern on the medial tibial plateau does not extend to the posterior margin of the tibia, and in all the cases there is intact articular cartilage on the posterior margin of the medial tibial plateau. ${ }^{1,2}$

In a proportion of patients with AMOA, a preoperative AP radiograph demonstrates the presence of mediolateral subluxation of the femur on the tibia. It is typically seen when there is significant loss of bone from the medial compartment (varus $>10^{\circ}$ ) and this subluxation persists with a varus stress view. The Oxford Group suggests that in such cases, if the valgus and varus stress views show complete reduction of the mediolateral subluxation, the presence of preoperative subluxation can be safely ignored. ${ }^{4}$ If the subluxation persists, it is indicative of anterior cruciate ligament $(A C L)$ deficiency and is therefore a contraindication for Oxford UKA (OUKA). ${ }^{2}$ Although this has been advocated, no studies exist comparing the long-term results of OUKA in patients with correctable subluxation with those without any subluxation.

Does the subluxation on weight-bearing knee X-rays affect the results and outcome of UKA?

This single centre, single surgeon cohort study of consecutive cases has two aims: first, to present early prospective $(P)$ results of OUKA in patients with AMOA between patients with correctable preoperative mediolateral TF subluxation and those without, from an independent centre; and second, to similarly compare the outcomes of a larger medium-term retrospective (R) AMOA cohort followed up by the same surgeon until 2020.

\section{Methods}

The prospective cohort $(\mathrm{P})$ study comprised 272 consecutive AMOA knees (248 patients) treated with medial OUKA (Zimmer Biomet, Warsaw, USA) over a 31-month period from November 2017 to May 2020. The larger retrospective cohort (R), comprising 436 cases from May 2012 to October 2017, was then similarly evaluated according to the selection criteria for OUKA as per the published recommendations..$^{2-4}$ All patients underwent a standardised preoperative work-up including detailed clinical assessments and a series of radiographs as described previously. ${ }^{5}$ Preoperative Oxford Knee Score (OKS) ${ }^{6}$ and range of movement (ROM) was recorded. The ACL status and integrity of the lateral TF compartment were confirmed intraoperatively. If $A C L$ was found to be friable and fragmented or absent, the patient underwent a total knee arthroplasty (TKA). In addition, the tibial wear pattern was carefully recorded using a method described by White et al. ${ }^{1}$ The wear pattern was labelled as either anterior, or central or posterior according to the location of the deepest area of wear in relation to the AP tibial plateau dimension. All plain radiographs were assessed by an independent assessor for the presence or absence of mediolateral TF subluxation and patients were grouped accordingly into group 1 (patients with AMOA without any evidence of mediolateral subluxation on preoperative weight-bearing $A P$ radiographs, Figures $1 \mathrm{a}-\mathrm{c}$ ) and group 2 (patients with AMOA with presence of mediolateral subluxation on preoperative weightbearing AP radiographs, Figures $2 a-c$ ). In all cases in group 2, the mediolateral subluxation completely corrected on valgus stress view with parallel reduction of the lateral joint space thereby confirming the suitability for OUKA.

To simplify the assessment of subluxation on the AP views, it was defined as any overhang of the femoral condyle (excluding osteophytes) over the medial border of the tibia.

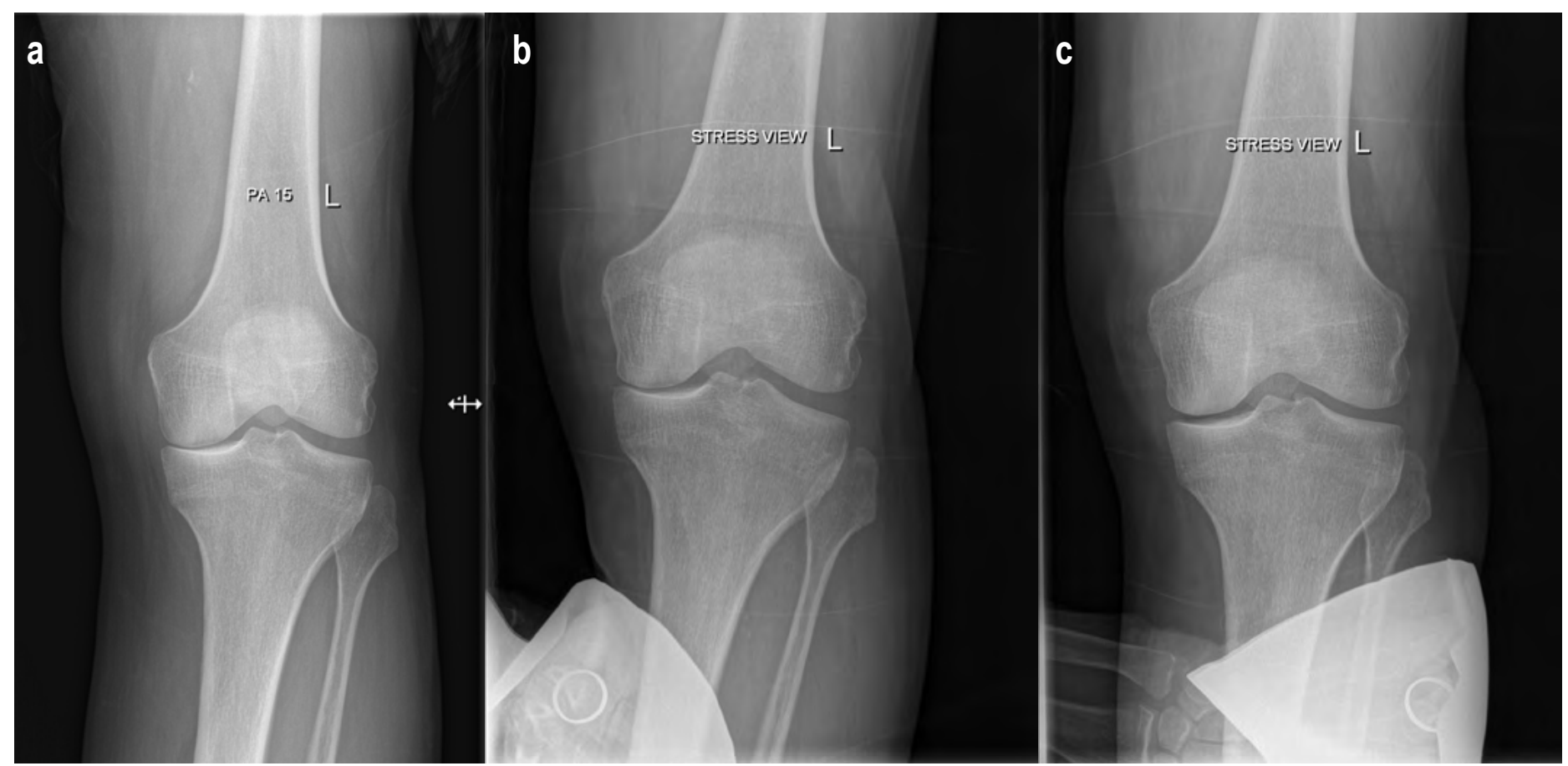

Figure 1. Group 1 preoperative radiographs. a) $15^{\circ} \mathrm{AP}$; b) varus stress view; c) valgus stress view 


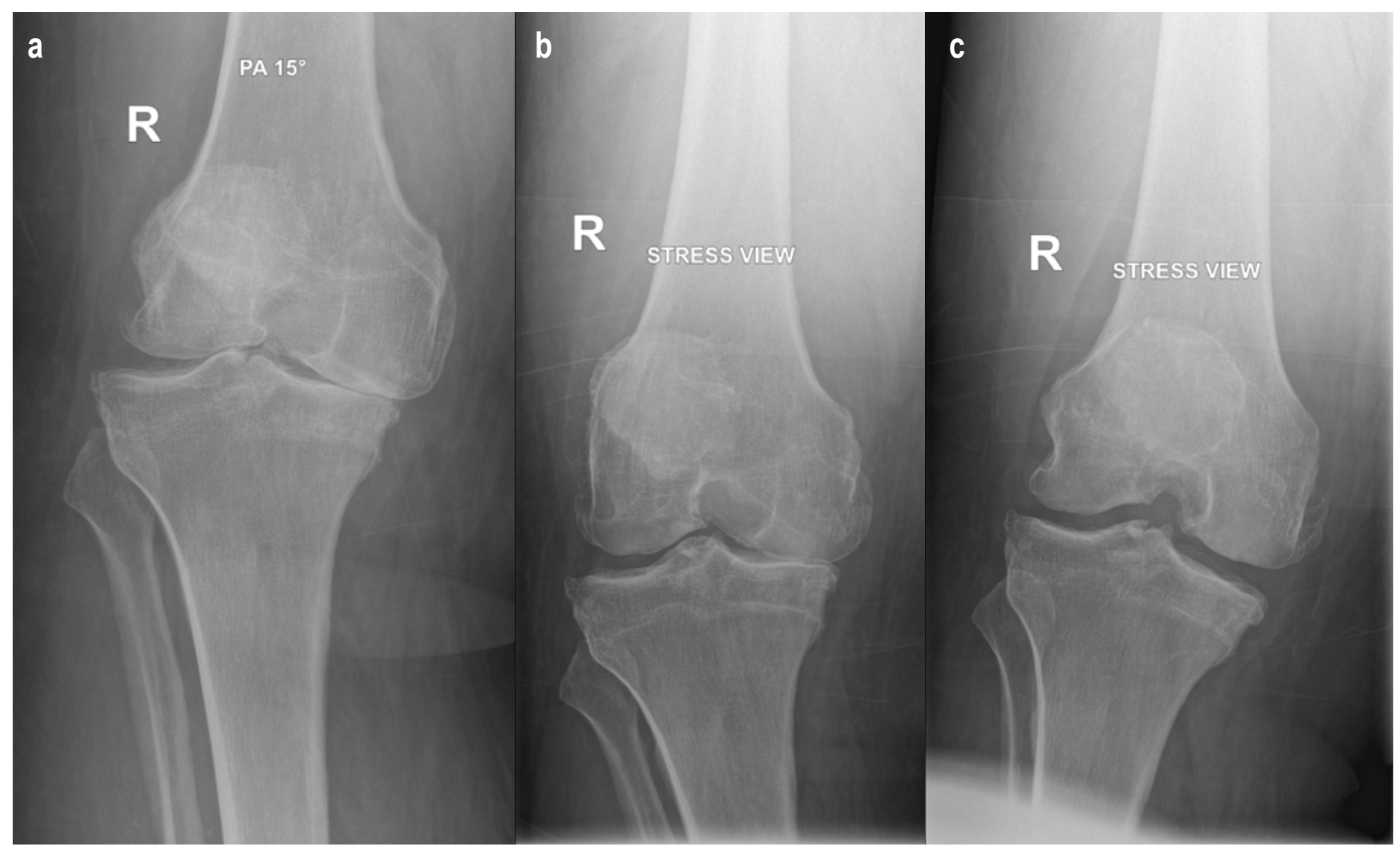

Figure 2. Group 2 preoperative radiographs. a) $15^{\circ} \mathrm{AP}$; b) varus stress view; c) valgus stress view

All patients underwent a cementless medial OUKA using the recommended surgical technique with Microplasty ${ }^{\circledR}$ instrumentation with standardised postoperative management. ${ }^{7}$ Patients were followed up at predetermined regular intervals (three months and then annually after surgery) with clinical and radiological assessment. Clinical assessment included OKS, a validated and widely used patient-reported outcome measure (PROM) and active ROM. All complications and/or further interventions on the index knee were recorded on an anonymised secure database. Any surgical intervention needed for removal or exchange of an existing implant or addition of another implant was labelled as revision.

\section{Statistical analysis}

Description of categorical variables was reported as a number and percentage. Associations between categorical variables were evaluated using chi-square $\left(\mathrm{X}^{2}\right)$ or Fisher's exact tests as appropriate. Continuous variables were summarised and presented as mean and range, or as median and interquartile range (IQR). A student's t-test for normally distributed data or Mann-Whitney $U$ test for non-normally distributed data was used to compare group differences in continuous variables. Survival analysis methods such as the Kaplan-Meier survival curves and logrank test were utilised to assess the patterns of implant survival between patients' characteristics. The multivariable Cox proportional hazards model was used to fit the predictive model for time to revision. A two-sided $5 \%$ significance level was used in all the statistical tests.

\section{Results}

The prospective $(\mathrm{P})$ cohort of 272 knees (248 patients) included $162(60 \%)$ men and $110(40 \%)$ women with an average age of 64 $(40-92 ; S D=10)$ years at time of operation. The mean follow-up was 20 months (range 4-34; SD = 10). The mean postoperative OKS in the non-revised knees (at the time of last follow-up) was 43 (range 14-48; SD = 6.3), while for the revised knees it was 44 (range 26-48; SD = 5.6). The mean ROM was $0.3^{\circ}$ (range 0-3; $\mathrm{SD}=0.86$ ) to $140^{\circ}$ (range $120-150 ; \mathrm{SD}=6.2$ ).

The retrospective $(R)$ cohort of 436 knees (388 patients; 175 [40\%] females and 261 [60\%] males) had an average age of 64 years (range $42-87, S D=8.7$ ) at operation. The mean postoperative follow-up was 54 months. The mean postoperative OKS in the nonrevised knees (at the time of last follow-up) was 44 (range 12-48, $\mathrm{SD}=5.7$ ), while for the revised knee it was 42 (range 22-48, SD $=8.0$ ). The mean ROM for this cohort was $0.68^{\circ}$ (range $0-5, \mathrm{SD}=$ 1.3 ) to $138^{\circ}$ (range $110-150, S D=8.2$ ).

The patient demographics (Table I), implant survival rates (Table II), and clinical outcomes and complications (Table III) for group 1 and group 2 in the respective cohorts $P$ and $R$ are summarised accordingly. The two groups were well matched for all relevant patient demographics as well as preoperative scores, ROM, followup period and tibial wear patterns.

The complications were not associated with a specific wear pattern.

\section{Reasons for revision}

In total, six knees underwent revision at a mean of 25 months (SD = 10.9; range: 8.1-33.2 months) post base year of follow-up in the $\mathrm{P}$ cohort. These included two for tibial subsidence, two for bearing dislocation and two for progression of arthritis in the lateral compartment. The $\mathrm{R}$ cohort had 23 knees that underwent revision, and these had a slightly longer duration before revisions. The detail of the complications and procedures performed are detailed in Table III.

The life table analysis for patients who had surgery between 2012 and 2017 ( $\mathrm{R}$ cohort) is presented in Table /I with the 


\begin{tabular}{|c|c|c|c|c|}
\hline \multirow{2}{*}{ Category } & \multicolumn{2}{|c|}{ Prospective (P) cohort } & \multicolumn{2}{|c|}{ Retrospective (R) cohort } \\
\hline & Group 1 & Group 2 & Group 1 & Group 2 \\
\hline Cases & 228 & 44 & 352 & 84 \\
\hline Age in years at operation; mean (SD) & $64(9.5)$ & $66(11.2)$ & $65(8.8)$ & $64(8.5)$ \\
\hline Males & $64(9.5)$ & $64(9.9)$ & $65(8.4)$ & $63(8.6)$ \\
\hline Females & $64(9.6)$ & $70(13.0)$ & $64(9.3)$ & $64(8.4)$ \\
\hline \multicolumn{5}{|l|}{ Tibial wear pattern: } \\
\hline Anterior & $51(22 \%)$ & $5(11 \%)$ & $87(25 \%)$ & $10(12 \%)$ \\
\hline Central & $161(71 \%)$ & $35(80 \%)$ & $247(70 \%)$ & $67(80 \%)$ \\
\hline Posterior & $16(7 \%)$ & $4(9 \%)$ & $18(5 \%)$ & $7(8 \%)$ \\
\hline Preoperative ROM; mean (from-to) & $3-128^{\circ}$ & $4-129^{\circ}$ & $2-131^{\circ}$ & $3-126^{\circ}$ \\
\hline Preoperative OKS; mean (SD) & $21(8.1)$ & $21(10.1)$ & $22(8.0)$ & $23(8.6)$ \\
\hline
\end{tabular}

SD: standard deviation; ROM: range of movement; OKS: Oxford Knee Score

respective implant survival for group 1 and group 2. The first three years' implant survival for patients in both group 1 and 2 was $100 \%$. The implant survival in the subsequent two years was $99 \%$ (95\% confidence interval [Cl]: 96.9-99.6) among those who were diagnosed without mediolateral subluxation (group 1) and $96 \%$ (95\% Cl: 89.2-98.8) among those with mediolateral subluxation (group 2) respectively. The difference between the two groups was statistically significant overall $(p=0.0097)$ over the followup period. The $\mathrm{P}$ cohort had only three years of follow-up and in that period, survival for group 1 was $99 \%$ (95\% Cl: 96-99.6) while group 2 was $93 \%(95 \% \mathrm{Cl}: 80.3-97.8)$. Figure 3 shows the failure patterns in the two groups for both cohorts.

Multivariate Cox regression analysis showed that presence or absence of mediolateral subluxation was a significant independent
Table II: Life table analysis with $95 \% \mathrm{Cl}$ for implant revision for any cause in the 2012-2017 (R) cohort

\begin{tabular}{lcccc} 
Follow-up & \multicolumn{2}{c}{ Group 1 } & \multicolumn{2}{c}{ Group 2 } \\
\cline { 2 - 5 } (years) & $\begin{array}{c}\text { No. at } \\
\text { start }\end{array}$ & $\begin{array}{c}\text { Survival } \\
(95 \% \mathrm{Cl})\end{array}$ & $\begin{array}{c}\text { No. at } \\
\text { start }\end{array}$ & $\begin{array}{c}\text { Survival } \\
(95 \% \mathrm{Cl})\end{array}$ \\
\hline $0-3$ (base) & 352 & $100 \%$ & 84 & $100 \%$ \\
\hline $4-5$ & 339 & $\begin{array}{c}99 \% \\
(96.9-99.6 \%)\end{array}$ & 83 & $\begin{array}{c}96 \% \\
(89.2-98.8 \%)\end{array}$ \\
\hline $6-8$ & 132 & $\begin{array}{c}93 \% \\
(88.3-96.5 \%)\end{array}$ & 52 & $\begin{array}{c}80 \% \\
(66.7-88.1 \%)\end{array}$ \\
\hline
\end{tabular}

$\mathrm{Cl}$ : confidence interval

Table III: Clinical outcomes and complications for the two groups in cohort

\begin{tabular}{|c|c|c|c|c|}
\hline \multirow[b]{2}{*}{ Category } & \multicolumn{2}{|c|}{ Prospective $(\mathrm{P})$ cohort } & \multicolumn{2}{|c|}{ Retrospective (R) cohort } \\
\hline & $\begin{array}{l}\text { Group } 1 \\
(n=228)\end{array}$ & $\begin{array}{l}\text { Group } 2 \\
(n=44)\end{array}$ & $\begin{array}{l}\text { Group } 1 \\
(n=352)\end{array}$ & $\begin{array}{l}\text { Group } 2 \\
(n=84)\end{array}$ \\
\hline Follow-up period in months; mean (SD) & $21(8.8)$ & $18(8.4)$ & $57(15.9)$ & $66(16.0)$ \\
\hline Postoperative ROM; mean (from-to) & $0.3-140^{\circ}$ & $0-138^{\circ}$ & $1-138^{\circ}$ & $0-138^{\circ}$ \\
\hline Most recent postoperative OKS; mean (SD) & $43(6.3)$ & $44(5.6)$ & $44(5.7)$ & $43(8.0)$ \\
\hline Complications needing revision surgery & $3(1 \%)$ & $3(7 \%)$ & $11(3 \%)$ & $12(14 \%)$ \\
\hline Average period to implant failure in months; mean (SD) & $24(13.5)$ & $27(10.3)$ & $63(17.1)$ & $65(16.6)$ \\
\hline $\begin{array}{l}\text { Bearing dislocation - with revision of medial UKA (polyethylene } \\
\text { replaced) }\end{array}$ & 0 & 1 & 1 & 2 \\
\hline Bearing dislocation - with revision of medial UKA (implant replaced) & 0 & 1 & 0 & 0 \\
\hline Lateral compartment OA - with revision to lateral UKA & 2 & 0 & 3 & 3 \\
\hline Tibial subsidence - with revision of medial UKA (implant replaced) & 1 & 1 & 1 & 0 \\
\hline $\begin{array}{l}\text { Tibial subsidence - with revision of medial UKA (polyethylene } \\
\text { replaced) }\end{array}$ & 0 & 0 & 2 & 0 \\
\hline $\begin{array}{l}\text { Avascular necrosis in the lateral compartment - with revision to } \\
\text { lateral UKA }\end{array}$ & 0 & 0 & 1 & 0 \\
\hline Tibia fracture - with revision to TKA & 0 & 0 & 0 & 2 \\
\hline Impingement - with revision of medial UKA (implant replaced) & 0 & 0 & 0 & 1 \\
\hline $\begin{array}{l}\text { ACL trauma and polyethylene dislocation - with revision of medial } \\
\text { UKA (polyethylene replaced) and ACL reconstruction }\end{array}$ & 0 & 0 & 0 & 1 \\
\hline Loose prosthesis - with revision to TKA & 0 & 0 & 0 & 1 \\
\hline No bone growth to attach prosthesis - with revision to TKA & 0 & 0 & 1 & 0 \\
\hline $\begin{array}{l}\text { Complication unknown - patients underwent revision surgery to } \\
\text { TKA from other surgeons }\end{array}$ & 0 & 0 & 2 & 2 \\
\hline
\end{tabular}

SD: standard deviation; ROM: range of movement; OKS: Oxford Knee Score; UKA: unicompartmental knee arthroplasty; OA: osteoarthritis; TKA: total knee arthroplasty;

ACL: anterior cruciate ligament 
a) Retrospectively

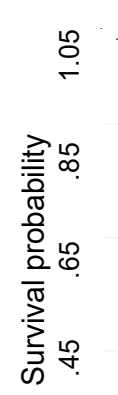

$\stackrel{ก}{ก}$ 0

20
40

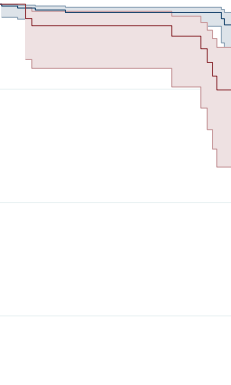

60

80

100 b) Prospectively

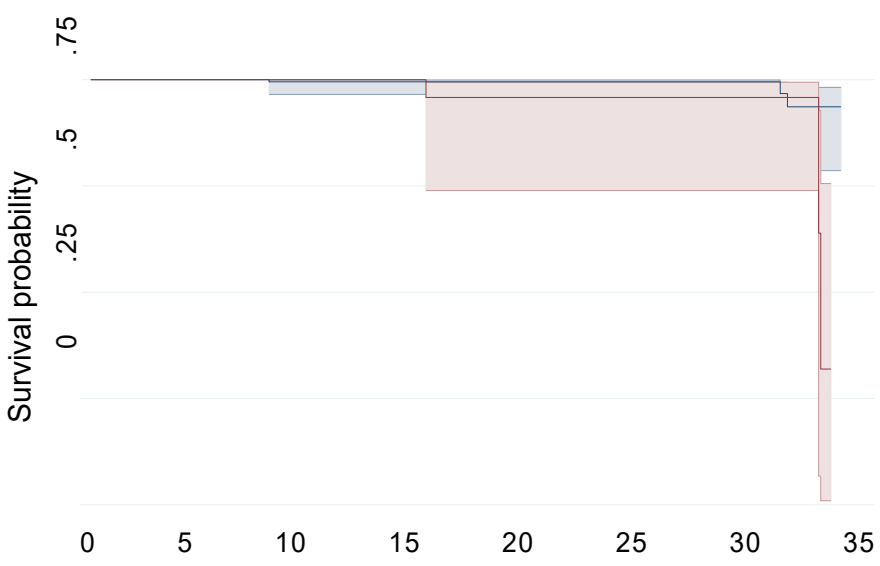

Time to failure in months

$\begin{array}{ll}95 \% \mathrm{Cl} & 95 \% \mathrm{Cl} \\ \text { Group 1 } & \text { Group 2 }\end{array}$

Time to failure in months

$\begin{array}{ll}95 \% \mathrm{Cl} & 95 \% \mathrm{Cl} \\ \text { Group 1 } & \text { Group 2 }\end{array}$

Figure 3. Surgical failure in group 1 and group 2 by the presence or absence of mediolateral subluxation on preoperative radiographs in patients followed up a) retrospectively and b) prospectively

predictor of implant failure (Table IV). A patient with preoperative mediolateral subluxation had, on average, a three times higher risk of surgical failure (adjusted hazard ratio $[\mathrm{aHR}]=3.3 ; 95 \% \mathrm{Cl}$ : $1.4-8.7 ; p=0.0170$ ) compared to a patient without mediolateral subluxation. Age, sex and wear pattern were not significantly associated with the risk of implant failure in this cohort (Table IV).

\section{Discussion}

This is the first prospective study to assess the impact of preoperative correctable mediolateral subluxation on the outcomes of UKA in patients with AMOA. Although this is a short prospective study, it confirms the higher failure rate, contrary to the previous recommendations in the literature, when compared to those with AMOA without preoperative mediolateral subluxation. ${ }^{4}$

AMOA knee is an ideal indication for UKA. Various studies have demonstrated the clinical effectiveness and cost-savings of UKA over TKA in such patients. ${ }^{8-12}$ In a significant proportion of patients, preoperative AP radiographs reveal the presence of mediolateral subluxation. Although the exact aetiology for such subluxation is unknown, it is believed to be associated with significant wear and/or bone loss and potentially ACL deficiency - the latter being a contraindication for mobile-bearing UKA. ${ }^{4}$ To ascertain the suitability of such patients for UKA, it is recommended that patients should be assessed using stress views - particularly the valgus stress - and intraoperative assessment of the lateral compartment as well as $A C L$ integrity. ${ }^{5}$ If valgus stress and intraoperative inspection confirms suitability for UKA, patients could be safely offered a UKA. In this series, we prospectively collected data on all the patients undergoing UKA. This included careful recording of preoperative patient demographics including radiological stress views, intraoperative assessment for suitability for UKA, tibial wear patterns and regular clinical follow-up at predetermined intervals. In our cohort we noted correctable mediolateral subluxation in $27 \%$ of cases. The implant survival was significantly inferior in patients with correctable mediolateral subluxation compared to those without subluxation. There were no significant differences in demographics between the two patient groups. Although the reasons for implant failure were similar in the two patient cohorts, the frequency of bearing dislocation was significantly higher in patients with mediolateral subluxation.

The assessment of wear patterns was compared to the area of wear (Table V), and no association of complications with a specific wear pattern could be found.

If we assess the risk of implant revision based on the pattern of tibial wear, it is interesting to note that the risk increases when the wear pattern changes from anterior to central or posterior. The central/posterior area of wear may contribute to pseudolaxity and higher incidence of bearing dislocation. Although the centre of the deepest portion of the wear pattern was posterior to midline in none of the cases, the wear extended to the posterior margin of the medial tibial plateau. In all cases, the ACL was functionally intact

Table IV: Factors affecting time to failure in cohort: multivariable Cox regression model

\begin{tabular}{|c|c|c|c|c|c|}
\hline \multirow{2}{*}{ Factor } & & \multicolumn{2}{|c|}{ Prospective (P) cohort } & \multicolumn{2}{|c|}{ Retrospective (R) cohort } \\
\hline & & aHR $(95 \% \mathrm{CI})$ & p-value & $\operatorname{aHR}(95 \% \mathrm{CI})$ & p-value \\
\hline \multirow[t]{2}{*}{ Mediolateral subluxation } & Group 1 (subluxation absent) & 1 & & 1 & \\
\hline & Group 2 (subluxation present) & $11(1.67-66.1)$ & 0.012 & $2.9(1.25-6.86)$ & 0.013 \\
\hline \multirow[t]{2}{*}{ Sex } & Female & 1 & & 1 & \\
\hline & Male & $0.41(0.06-2.92)$ & 0.372 & $0.67(0.29-1.54)$ & 0.349 \\
\hline \multirow[t]{2}{*}{ Wear pattern } & Anterior & 1 & & 1 & \\
\hline & Central/posterior & $0.82(0.08-8.58)$ & 0.869 & $1.12(0.37-3.37)$ & 0.841 \\
\hline Age at surgery & & $1.0(0.91-1.1)$ & 0.959 & $1.0(0.56-1.05)$ & 0.926 \\
\hline
\end{tabular}

aHR: adjusted hazard ratio; Cl: confidence interval 
Table V: Patient characteristics for failed vs not failed implants

\begin{tabular}{|c|c|c|c|c|c|c|c|}
\hline \multirow[b]{2}{*}{ Variable } & & \multicolumn{3}{|c|}{ Prospective (P) cohort } & \multicolumn{3}{|c|}{ Retrospective (R) cohort } \\
\hline & & $\begin{array}{c}\text { Surgery failed, } \\
\text { n (\%) }\end{array}$ & $\begin{array}{l}\text { Surgery not } \\
\text { failed, n (\%) }\end{array}$ & p-value & $\begin{array}{l}\text { Surgery failed, } \\
\text { n (\%) }\end{array}$ & $\begin{array}{l}\text { Surgery not } \\
\text { failed, n (\%) }\end{array}$ & p-value \\
\hline \multirow[t]{2}{*}{ Sex } & Female & $2(2)$ & $108(98)$ & $0.535^{\star}$ & $11(6)$ & $164(94)$ & $0.440^{*}$ \\
\hline & Male & $4(3)$ & $158(97)$ & & $12(5)$ & $249(95)$ & \\
\hline \multicolumn{2}{|l|}{ Age in years (range) } & $64(57-72)$ & $64(40-92)$ & $0.865^{++}$ & $64(48-76)$ & $65(42-87)$ & $0.907^{++}$ \\
\hline \multirow{2}{*}{$\begin{array}{l}\text { Mediolateral } \\
\text { subluxation }\end{array}$} & Group 1 & $3(1.3)$ & $225(98.7)$ & $0.056^{*}$ & $11(3)$ & $341(97)$ & $<0.001^{*}$ \\
\hline & Group 2 & $3(6.8)$ & $41(93.2)$ & & $12(14)$ & $72(86)$ & \\
\hline \multirow[t]{3}{*}{ Tibial wear pattern } & Anterior & $1(2)$ & $55(98)$ & $0.739^{*}$ & $4(4)$ & $93(96)$ & $0.925^{*}$ \\
\hline & Central & $5(3)$ & $191(97)$ & & $18(6)$ & $296(94)$ & \\
\hline & Posterior & $0(0)$ & $20(100)$ & & $1(4)$ & $24(96)$ & \\
\hline
\end{tabular}

${ }^{*}$ chi-squared test

++ independent-samples student's t-test

(on intraoperative assessment), thereby confirming the patient's suitability for UKA as per established criteria.

This study has certain limitations. It is a single surgeon, single centre study with a short prospective element conforming to the trend seen in the larger retrospective cohort which cannot yet be generalised. The prospective cohort also had very few failures (only six) for both groups, which could increase uncertainty in the risk estimate due to limited power. However, analysis of the prospective $(\mathrm{P})$ cohort is still under continuous evaluation, and will be submitted when the five-year mean has been achieved. The study confirms association (and not causality) between higher implant failures and patients with pre-existing correctable mediolateral subluxation in patients with AMOA.

The indications for surgery, surgical technique and postoperative regimen were standardised. All patients were followed up with detailed records of their clinical outcomes and complications. The follow-up is adequate and overall implant survival is similar to other reported series with the use of cementless OUKA.

Further work is needed to establish if similar findings are observed by other researchers, and attempts should be made to understand the association between smoking status, tibial wear patterns, coronal subluxation and implant failure.

\section{Conclusion}

The AMOA with anterior wear and without mediolateral subluxation is the most suitable knee for UKA. In patients with correctable preoperative mediolateral subluxation, caution must be exercised when offering a cementless UKA.

\section{Acknowledgements}

The authors would like to thank Margaret Houman (research manager) and Andricha Viljoen (researcher) for their contributions.

\section{Ethics statement}

All procedures performed in studies involving human participants were in accordance with the ethical standards of the institutional and/or national research committee and with the 1964 Helsinki declaration and its later amendments or comparable ethical standards.

All procedures were in accordance with the ethical approval obtained from the Human Research Ethics Committee at the University of the Witwatersrand (Wits) with clearance certificate numbers M1704111 and M1704112. All patients provided informed consent for inclusion in the study.

\section{Declaration}

The authors declare authorship of this article and that they have followed sound scientific research practice. This research is original and does not transgress plagiarism policies.

Professor Pandit is a National Institute for Health Research (NIHR) Senior Investigator The views expressed in this article are those of the author(s) and not necessarily those of the NIHR, or the Department of Health and Social Care.

\section{Author contributions}

CRO: Primary author, study conceptualisation, design, data collection and contribution, first draft preparation, manuscript preparation and revision, submission of final manuscript

IM: Design, data analysis, manuscript preparation and revision

SM: Design, manuscript preparation and revision, supervisor, final approval of manuscript version submitted to the journal

HP: Design, manuscript preparation and revision, critical revision for important intellectual content

\section{ORCID}

Oosthuizen CR (1) https://orcid.org/0000-0001-9973-5290

Maposa I https://orcid.org/0000-0002-3448-4096

Magobotha S https://orcid.org/0000-0003-4774-0420

Pandit H https://orcid.org/0000-0001-7392-8561

\section{References}

1. White SH, Ludkowski PF, Goodfellow JW. Anteromedial osteoarthritis of the knee. J Bone Joint Surg Br. 1991;73(4):582-86. https://doi.org/10.1302/0301-620X.73B4.2071640.

2. Goodfellow J, O'Connor J, Pandit H, et al. Unicompartmental arthroplasty with the Oxford Knee. 2nd ed. Goodfellow Publishers Limited; 2015.

3. Hamilton TW, Pandit HG, Lombardi AV, et al. Radiological decision aid to determine suitability for medial unicompartmental knee arthroplasty: development and preliminary validation. Bone Joint J. 2016;98-B(10 Suppl B):3-10. https://doi.org/10.1302/0301620X.98B10.BJJ-2016-0432.R1.

4. Kendrick BJ, Rout R, Bottomley NJ, et al. The implications of damage to the lateral femoral condyle on medial unicompartmental knee replacement. J Bone Surg Br. 2010;92(3):374-79. https://doi.org/10.1302/0301-620X.92B3.23561.

5. Oosthuizen CR, Takahashi T, Rogan M, et al. The knee osteoarthritis grading system for arthroplasty. J Arthroplasty. 2019;34:450-55. https://doi.org/10.1016/j.arth.2018.11.011.

6. Murray DW, Fitzpatrick R, Rogers $\mathrm{K}$, et al. The use of the Oxford hip and knee scores. J Bone Joint Surg Br. 2007;89(8):1010-14. https://doi.org/10.1302/0301-620X.89B8.19424.

7. Bell SW, Stoddard J, Bennett C, London NJ. Accuracy and early outcomes in medial unicompartmental knee arthroplasty performed using patient specific instrumentation. Knee 2014;21(Suppl 1):S33-6. https://doi.org/10.1016/S0968-0160(14)50007-5

8. Kazarian GS, Lonner JH, Maltenfort MG, et al. Cost-effectiveness of surgical and nonsurgical treatments for unicompartmental knee arthritis: a Markov model. J Bone Joint Surg Am. 2018;100(19):1653-60. https://doi.org/10.2106/JBJS.17.00837.

9. Campi S, Pandit H, Hooper G, et al. Ten-year survival and seven-year functional results of cementless Oxford unicompartmental knee replacement: A prospective consecutive series of our first 1000 cases. Knee. 2018;25(6):1231-37. https://doi.org/10.1016/j.knee.2018.07.012.

10. Burn E, Liddle AD, Hamilton TW, et al. Cost-effectiveness of unicompartmental compared to total knee replacement: a population-based study using data from the National Joint Registry for England and Wales. BMJ Open. 2018;8(4):e020977. https://doi.org/10.1136/ bmjopen-2017-020977.

11. Hamilton TW, Pandit HG, Jenkins C, et al. Evidence-based indications for mobile-bearing unicompartmental knee arthroplasty in a consecutive cohort of thousand knees. J Arthroplasty. 2017;32(6):1779-85. https://doi.org/10.1016/j.arth.2016.12.036.

12. Beard DJ, Davies LJ, Cook JA, et al. TOPKAT Study Group. The clinical and cost-effectiveness of total versus partial knee replacement in patients with medial compartment osteoarthritis (TOPKAT): 5 -year outcomes of a randomised controlled trial. Lancet. 2019:394(10200):746-56. https://doi.org/10.1016/S0140-6736(19)31281-4. 